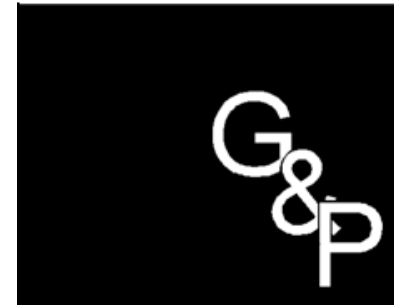

GESTÃO

$\&$

PRODUÇÃO

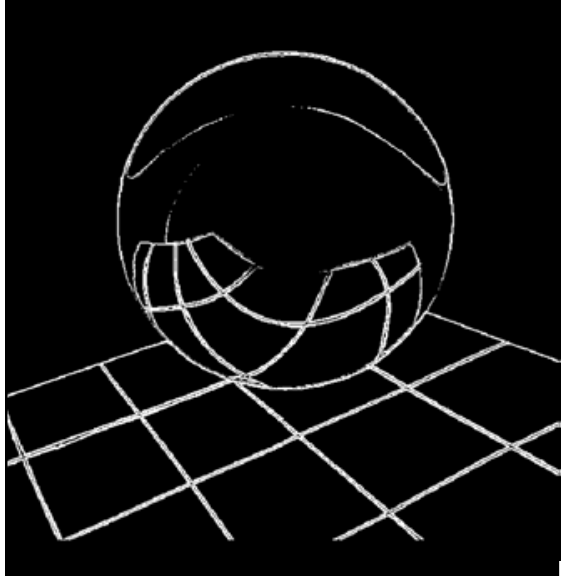

v.6, n.3, p. 201-218, dez. 1999

\section{IMPACTO DA TECNOLOGIA DE INFORMAÇÃO NO SUPPLY CHAIN MANAGEMENT: UM ESTUDO MULTICASO SOBRE A ADOÇÃO DE EDI ENTRE VAREJO E INDÚSTRIA AGROALIMENTAR}

\author{
Andrea Lago da Silva \\ Depto de Engenharia de Produção \\ Universidade Federal de São Carlos \\ E-mail: deialago@power.ufscar.br
}

Adalberto A. Fischmann Faculdade de Economia, Administração e Contabilidade Universidade de São Paulo E-mail: aafischm@usp.br

\title{
Resumo
}

As tecnologias de informação têm alterado as formas de coordenação entre os diferentes elos da cadeia de suprimentos. A coordenação pode ser entendida como a habilidade de transmitir informação, estímulos e controles ao longo das etapas seqüenciais que integram o conjunto de atividades necessárias para atender o mercado (FARINA \& ZYLBERSZTAJN, 1994). O conjunto destas etapas é o que tem sido chamado de Supply Chain ou Cadeia de Suprimentos. Neste artigo, discute-se alguns casos de adoção de uma tecnologia de informação, o EDI (troca eletrônica de dados) como ferramenta de coordenação entre varejistas e indústrias agroalimentares. Conclui-se que o processo de adoção é relativamente recente para que se possa mensurar resultados quantitativos e qualitativos significativos, mas já se observa alterações na freqüencia de desabastecimento, em estoques melhor dimensionados e vendas maiores em decorrência da maior disponibilidade de mercadorias. Sinalizam-se também mudanças qualitativas, como alteração na função do vendedor tradicional, maior interação entre as áreas técnicas, com um aprendizado comum das novas formas de usar a tecnologia e o importante papel da confiança nos relacionamentos interorganizações.

Palavras-chave: cadeia de suprimentos, tecnologia de informação, EDI.

\section{Introdução}

Vos últimos anos, o uso de tecnologia de informação tem sido apontado como uma vantagem competitiva essencial para organizações que buscam diferenciar-se diante de seus clientes. Tal cenário não difere ao se tratar do varejo e da indústria agroalimentar, tipo de 
negócio no qual os processos de trocas são relativamente mais complexos uma vez que seus produtos têm características específicas a serem consideradas. Dentre elas pode-se citar alto grau de perecibilidade (com utilização rigorosa da cadeia do frio, em muitos casos), sazonalidade e dispersão de produção agropecuária, e diversas variáveis que afetam o comportamento do consumidor (diferentes ocasiões de consumo, preocupação com conveniência e aspectos relacionados à saúde) (SILVA \& BATALHA, 1997).

HANDFIELD \& NICHOLS (1999) destacam que três grandes tendências têm despertado a atenção dos administradores: a revolução da informação (sua obtenção, análise e difusão), a diversidade das demandas dos clientes em termos de produtos e serviços (custos, qualidade, ciclo de compra e tecnologia) e a emergência de novas formas de relacionamentos interorganizações. Tais tendências podem ser observadas no crescimento e na difusão das idéias de Supply Chain Management (SCM ou Gestão da Cadeia de Suprimentos) e de Efficient Consumer Response (ECR ou Resposta Eficiente ao Consumidor).

Os avanços da tecnologia de informação têm facilitado mudanças na direção do fluxo da cadeia de suprimentos, que deixa de ser orientado da produção para o consumo e passa a ser puxado pela demanda do consumidor (BELL et al., 1997). Isso acontece a partir do momento em que os supermercados e seus fornecedores (os atacadistas e a indústria) passam a utilizar as informações coletadas pelos primeiros em seus terminais de ponto-de-venda, visando reorganizar o fluxo de abastecimento de acordo com o que os clientes efetivamente compram e valorizam. Nesse momento, percebem-se oportunidades de agregar valor a partir de um maior sortimento de produtos e da disponibilização de serviços.

O objetivo deste trabalho é discutir algumas mudanças ligadas a adoção de novas tecnologias de informação dentro da gestão da cadeia de suprimentos, tendo como foco a adoção de EDI pelos varejistas de auto-serviço (aqui chamados genericamente de varejistas) e seus fornecedores (indústrias) agroalimentares com sede em São Paulo e operação em todo Brasil.

A EAN Brasil - Associação Brasileira de Automação Comercial (1998) - afirma que EDI é um termo estabelecido internacionalmente para o processo de troca de documentos entre sistemas de informação de diferentes empresas, que possuem como característica básica a integração automática entre os sistemas com mínima intervenção manual. O EDI pode ser definido, segundo a mesma fonte, como a troca de mensagens parametrizadas (documentos com estrutura fixa e padronizada), entre os sistemas, como pedidos de produtos, nota fiscal, aviso de recebimento, posição de estoques, lista de títulos a serem pagos nos próximos dias, entre outros.

\section{Cadeia de Suprimentos e Tecnologia de Informação: Algumas Considerações Teóricas}

\subsection{Cadeia de Suprimentos, ECR e conceitos relacionados}

A noção básica de Supply Chain Management ou Gestão da Cadeia de Suprimentos, segundo BOWERSOX \& CLOSS (1996), é baseada na crença de que a eficiência ao longo do canal de distribuição pode ser melhorada pelo compartilhamento de informação e do planejamento conjunto entre seus diversos agentes. STERN \& EL-ANSARY (1992) definem os canais de distribuição como conjuntos de organizações interdependentes, envolvidas no processo de tornarem produtos ou serviços disponíveis para o uso ou consumo. Este autores ressaltam que essas organizações, longe de serem agentes passivos na satisfação da demanda, preocupando-se apenas em suprir produtos e serviços no lugar, quantidade, qualidade e preços esperados, atuam também como agentes estimuladores dessa demanda.

A busca de sintonia entre os diferentes agentes e a eficiência conjunta é exatamente o que a gestão de cadeias de suprimentos objetiva. A grande questão com que se defrontam atualmente os varejistas, indústrias e prestadores de 
serviços, porém, é como construir essa sintonia, aumentando a competitividade da cadeia como um todo. Tal sintonia, evidentemente não envolve apenas as atividades de logística entendidas como todas as atividades que envolvem colocar produtos disponíveis, onde e quando são desejados por seus consumidores (BOWERSOX \& CLOSS, 1996) - mas também a gestão de todos os processos envolvidos. De acordo com COOPER et al. (1997), existe uma diferença fundamental entre os conceitos de Gestão da Cadeia de Suprimentos e o de Gestão da Logística Integrada. Essa diferença diz respeito aos relacionamentos, e mesmo às parcerias entre empresas, no caso de a Gestão da Cadeia de Suprimentos envolverem maior gama de processos e funções do que no caso de Gestão da Logística Integrada. Ou seja, a Gestão da Cadeia de Suprimentos, no entender dos autores, acaba por modificar muitos dos processos organizacionais sob os quais a Logística não teria poder, nem conhecimento para interferir.

Um dos conceitos que permeiam qualquer trabalho com foco na melhoria da gestão da cadeia de suprimentos é o ECR ou Efficient Consumer Response, traduzido entre nós, como resposta eficiente ao consumidor. Em 1992 foi criado nos EUA o The Efficient Consumer Response Working Group juntando líderes tanto da chamada indústria quanto do setor de distribuição (o que nos EUA corresponde ao setor de grocery). A idéia era examinar a cadeia de suprimentos de produtos de mercearia, analisando a cadeia de valor dos fornecedoresdistribuidores e consumidores, determinando as melhorias em custos e serviços que poderiam ser obtidos a partir de mudanças em tecnologias e práticas de gestão. Segundo publicações do $E C R$ Working Group e da empresa de consultoria Kurt Salmon (Joint Industry Project, 1995) as empresas ao longo do canal de distribuição devem adotar algumas ferramentas do ECR com objetivo de aumentar vendas e oferecer maior valor ao consumidor final. Essas ferramentas objetivam melhorar a eficiência do sortimento (otimizar o mix de produtos e alocação de espaço, tendo como conseqüência o aumento de vendas e do giro de estoques), reposição (dinamizar o fluxo de produtos desde a produção até o checkout do distribuidor, pelo intermédio da gestão partilhada de estoques entre distribuidores e fornecedores, buscando reduzir custos de armazenagem e distribuição), promoção (identificar pontos de redução de custos, a partir da redução da complexidade dos acordos entre distribuidores e fornecedores que não agreguem valor ao consumidor final) e introdução de novos produtos (aumentar o índice de sucesso do lançamento de novos produtos por meio de troca de informação sobre vendas ao longo do tempo entre os parceiros).

O ECR, que desde então, tem se tornado um movimento com fóruns em diversos países, tem uma conexão direta com este trabalho. A idéia do ECR, segundo KEH \& PARK (1997:838), é que se trata de uma inovação tecnológica ampla que traz no seu bojo múltiplas inovações de caráter tecnológico e gerencial, que visam transformar as empresas do setor de distribuição agroalimentar em organizações mais eficientes e interconectadas.

Um ponto importante das iniciativas ligadas à filosofia ECR é o aprimoramento do fluxo de informação, tanto internamente às empresas, quanto na interação entre empresas dentro de uma cadeia de suprimentos qualquer. Esse aprimoramento é apoiado em um programa de investimento em tecnologia de informação, seja em sistemas de gestão como ERP (Enterprise Resources Planning), seja em código de barras, scanner e EDI.

O ECR pode ser visto como uma forma de implementar a Gestão da Cadeia de Suprimentos. O EDI pode ser considerado como uma tecnologia-chave para o ECR na relação entre indústrias e varejistas. Para a adoção dessa ferramenta muitos acordos e negociações devem ser realizados, não só pelas áreas de logística de ambos os parceiros, mas também pelas de informática/sistemas (no que diz respeito a padrões de codificação) e entre as áreas comerciais e de compras. Um desses acordos diz 
respeito à disponibilização, por parte do varejista, do relatório de vendas por checkout, dos produtos para seu fornecedor. Tal acordo envolve inúmeras negociações por tratar de informações estratégicas para ambos os lados da parceria. Esse procedimento foge do escopo da área de logística, por mais que seja ampliado. Uma das formas de construir a integração entre diferentes áreas e diferentes empresas envolvidas em negociações é pela formação de redes de empresas.

Uma condição básica para que se implemente a gestão da cadeia de suprimentos, no entender de COOPER et al. (1997), é que exista algum nível de coordenação intra-organização e através dos limites organizacionais. Coordenação é definida como a capacidade que um sistema (no caso, a cadeia de suprimentos) tem de se estruturar para atender seus objetivos, que estão relacionados à obtenção de vantagens competitivas (FARINA \& ZYLBERSZTAJN, 1994). Os mesmos autores salientam que a coordenação envolve um processo de transmissão de informações, estímulos e controles ao longo da cadeia para que a mesma possa responder às mudanças no ambiente competitivo.

Em termos de realidade brasileira, no caso dos varejistas e das indústrias de bens de consumo, encontramos um bom exemplo de instituições ou grupos de instituições, com iniciativas que têm como objetivo a coordenação entre empresas para obter vantagens competitivas. $\mathrm{O}$ projeto do Sindicato do Comércio Varejista de Gêneros Alimentícios de São Paulo e Fundação Instituto de Administração da USP (Sincovaga/ FIA-USP) é um exemplo deste tipo de iniciativa. Esse projeto desenvolveu uma nova forma de atendimento aos pontos-de-venda, conectando-os às indústrias, via troca eletrônica de dados. A idéia era garantir condições de compra e entrega de mercadorias e, por conseqüência, maior sortimento aos varejistas e garantia da manutenção de clientes estrategicamente interessantes para a indústria. O Sincovaga/FIA-USP tem neste processo um papel de coordenador, na medida em que facilitou o processo de operacionalização do comércio eletrônico entre os parceiros, oferecendo estímulos e instituindo mecanismos de controle no sistema.

No caso da relação indústria-distribuidor (varejo-atacado-distribuidor), para que se implante mecanismos de coordenação e se alcance maior eficiência na gestão de suprimentos há necessidade de que os parceiros comerciais compartilhem informações para que, dentre outras razões:

- sirvam para que a indústria entenda as especificidades de cada cliente e possa atendê-lo de forma diferenciada, agregando valor (pelos serviços, por exemplo) à linha de produtos comercializada;

- sejam consideradas características como segmentação dos pontos-de-venda, tipo de clientes ao longo da cadeia de suprimentos, principalmente nas decisões de lançamento de novos produtos e no mix de cada loja.

Pode-se observar, segundo KONSYNSKI \& MCFARLAN (1990) algumas virtudes da parceria de informações:

- garante troca de grandes volumes de dados de forma precisa, instantânea e relativamente barata;

- a informação pode ser analisada, cruzada, correlacionada e guardada;

- reduz o risco de se investir sozinho em tecnologia;

- auxilia os parceiros a aprenderem juntos as diversas aplicações da nova tecnologia, e quais benefícios extrair dela com o intuito de agregar valor ao produto oferecido ao consumidor final;

- aproveita oportunidades criadas pela parceria de informações, como marketing cooperativo, parcerias intra-indústria, parceria clientefornecedor e parcerias para compra ou venda de tecnologia de informação.

\subsection{O Papel da Tecnologia da Informação na Gestão da Cadeia de Suprimentos}

COLLA (1997) sugere que as tecnologias de informação (usualmente conhecidas como TI), por suas mais diversas aplicações, asseguram 
que a comunicação - interna e externa à empresa - seja, com sua utilização, efetuada de forma mais rápida e eficaz, beneficiando os diferentes elos da cadeia de suprimentos.

De acordo com BOWERSOX \& CLOSS (1996), os administradores ligados à área de logística vêem a tecnologia de informação como a principal fonte de melhoria de produtividade e competitividade. Segundo os mesmos autores, diferente de outros recursos, a TI tem evoluído de forma a aumentar a velocidade e capacidade de transmissão de informação e, ao mesmo tempo, diminuindo seu custo. Os autores destacam cinco tecnologias que tem demonstrado vasta aplicação na área de logística: a troca eletrônica de dados (EDI), os computadores pessoais, a inteligência artificial, os sistemas de comunicação, os códigos de barras e os scanners. Neste trabalho, buscou-se analisar o uso de EDI como ferramenta de troca de informações entre diferentes empresas da cadeia de suprimentos.

\subsubsection{O EDI na Cadeia de Suprimentos}

\section{a) Antecedentes}

Uma das formas de operacionalizar a troca de informações entre empresas é, o que se convencionou chamar na década de 70, de IOS (Inter Organizational Systems) ou sistemas interorganizacionais. Trata-se de sistemas proprietários, desenvolvidos por grandes empresas (como o SABRE da American Airlines e o LeviLink da Levi Strauss). Esses sistemas, por sua natureza proprietária, enfrentaram resistências dos possíveis parceiros, que têm receio de perder sua autonomia e independência (VIJAYASARATHY \& ROBEY, 1997). Na década de 90, com a percepção da importância de agregar o fluxo de informações ao conceito de supply chain environment, alguns autores, como BAKOS (1991) e HANDIFIELD \& NICHOLS (1999:19), acreditam que muitas organizações vêm implementando IOIS (Interorganizational information systems), sistemas baseados em tecnologia da informação, que ultrapassam os limites organizacionais.
A partir do esforço de algumas associações, o problema tem sido solucionado pelo desenvolvimento de padrões estruturados que monitoram a troca de informações entre empresas, mediante meios eletrônicos, definidos como EDI. Uma vez adotados tais padrões, as empresas poderão transacionar eletronicamente entre si, sem a necessidade de grandes adaptações entre os parceiros. As adaptações devem ocorrer no âmbito de negociações/acordos comerciais e pouco tem a ver com a tecnologia adotada para a troca de informação.

\section{b) Mudanças}

BROWNING (1997:8-9) sugere que a tecnologia de informação traz consigo novas regras de gestão. Foco nos resultados é uma das novas regras e envolve criar demanda (mais do que administrá-la) e entregar produtos no tempo certo (mais do que tomar pedidos e gerenciar inventários). A regra seguinte é construir infraestrutura, pois as mudanças podem acontecer mais rápido do que a capacidade das pessoas em fazê-la, e não meramente na rapidez com que as máquinas podem fazê-la. Uma terceira regra é tentar definir desde o início quais são os objetivos do projeto e onde se pretende chegar. A última regra envolve trazer os clientes para dentro da empresa, para descobrir exatamente o que eles desejam.

COLLA (1997) sugere que existe uma alteração na divisão de tarefas entre os diferentes elos da cadeia, a partir da adoção de novas tecnologias de informação, como o EDI. Essa alteração se reflete na redistribuição de funções entre os diferentes agentes da cadeia. Um exemplo disso, segundo o autor, é o fato da indústria ter de inserir código de barras na concepção das suas embalagens de consumo e acondicionamento, para facilitar gestão e manuseio desde da fábrica até o ponto-de-venda.

\section{c) $O E D I$}

O EDI é uma ferramenta básica para implantação da reposição eficiente ou reposição automática. As empresas pesquisadas começaram o 
processo no padrão EDIFACT, trocando eletronicamente documentos simples, como pedido e nota fiscal, mas no passo seguinte a empresa cliente repassa aos seus fornecedores (já tendo calculado seus estoques mínimos e máximos e ponto de pedido) a posição de estoques ou os relatórios de vendas por produtos. De posse dessas informações, os fornecedores conseguem saber o que e quanto devem entregar de mercadoria. A implantação da reposição automática é, por diversas razões, o passo mais avançado do EDI. Isso porque envolve, primeiro um domínio das ferramentas mais simples, e além disso, exige disposição e tempo para que os dois parceiros acertem os parâmetros e já tenham um nível de confiança suficiente para passar dados (como posição de estoques, considerados estratégicos pelo cliente) e confiar nos prazos de reposição prometidos pelo fornecedor.

$\mathrm{Na}$ revisão de literatura sobre a adoção de EDI, são apontados diversos obstáculos a sua implementação nas empresas, dentre eles:

- incompatibilidade com os sistemas internos já existentes (MCGOWAN \& MADEY, 1998; NAVAJAS \& TAKAOKA, 1997);

- poucos benefícios diretos (MCGOWAN \& MADEY, 1998);

- resistência a mudanças nas empresas (GOTTARDI \& BOLISANI, 1996), principalmente por parte dos fornecedores (NAVAJAS \& TAKAOKA, 1997);

- necessidade de mudanças (NIEDERMAN, 1998);

- dificuldades na avaliação da relação custobenefício (GOTTARDI \& BOLISANI, 1996);

- muitas das empresas envolvidas requerem diferentes adaptações aos padrões escolhidos (NIEDERMAN, 1998).

Entre as vantagens advindas pela adoção de EDI encontram-se:

- imagem de vanguarda tecnológica (NAVAJAS \& TAKAOKA, 1997);

- ganhos de eficiência no abastecimento (NAVAJAS \& TAKAOKA, 1997) e redução de incerteza (MALTZ \& SRIVASTAVA, 1997);
- melhor qualidade das informações (NAVAJAS \& TAKAOKA, 1997), conseqüente aumento da capacidade de reação às mudanças do mercado e maior coordenação (GOTTARDI \& BOLISANI, 1996);

- aumento das habilidades da mão-de-obra relacionada a processamento de dados (NAVAJAS \& TAKAOKA, 1997);

- maior interação com os parceiros (NAVAJAS \& TAKAOKA, 1997);

- melhor gerenciamento de estoques e conseqüente redução de custos (ANVARI, 1992);

- melhora na prestação de serviço ao cliente, rapidez na comunicação e maior fidelidade de clientes (BANERJEE \& GOLHAR, 1994);

- diminuição de erros (BANERJEE \& GOLHAR, 1994).

GOTTARDI \& BOLISANI (1996:381) discordam quanto a algumas dessas vantagens. Argumentam que as economias referentes à diminuição de erros e aumento da agilidade no processo administrativo são pequenas em relação aos investimentos necessários, e o uso de papel raramente deixa de existir, a não ser que haja um alto nível de integração eletrônica entre os parceiros. Ressaltam também que a disponibilidade de tecnologia de ponta não é o principal requisito para a obtenção de benefícios do EDI. A maior dificuldade percebida, segundo os autores, é harmonizar os procedimentos e as estruturas organizacionais dos parceiros. Para chegar a tal harmonia, que não envolve apenas questões de padronização para troca de mensagens, os parceiros têm de formalizar acordos legais e organizacionais. Para que o investimento no desenvolvimento desses acordos seja compensador, ou seja, traga retornos, os volumes de informações e bens transacionados pelos parceiros devem ser significativos. Para os autores, no caso de outras tecnologias interativas, deve ser considerada a necessidade de massa crítica para a obtenção dos benefícios prometidos.

Os mesmos autores enfatizam que os maiores benefícios do EDI não emergem da tecnologia em si, mas das mudanças implementadas para a sua adoção em termos de produção, processos e 
novas formas de relacionamento, que melhorem a coordenação entre os parceiros. Eles mencionam também que o EDI pode ser uma ferramenta para a melhoria da coordenação interorganizações, principalmente no que diz respeito à rápida adaptação às mudanças do mercado. Segundo os autores, o EDI influencia fortemente na automação de transações entre diferentes organizações. Essas transações podem incluir relações verticais dentro de uma cadeia de valor (influenciando o poder de barganha entre clientes e fornecedores, e serviços de apoio) ou relações horizontais (alianças estratégicas, jointventures e redes de organizações).

\section{Metodologia}

A metodologia utilizada neste trabalho é o estudo multicaso. Segundo YIN (1994) o estudo de caso é uma pesquisa de natureza empírica que investiga um fenômeno atual dentro da situação em que ele ocorre, especialmente quando os limites entre o fenômeno e o contexto não são claros. O estudo multicaso é interessante nesta pesquisa, pois permite uma maior abrangência dos resultados, uma vez que ultrapassa os limites de unicidade de dados de uma só empresa.

A amostra, não probabilística, foi escolhida a partir de uma técnica de amostragem intencional ou por conveniência. A amostra compreendeu 3 grandes varejistas (que estavam trabalhando há pelo menos 12 meses com EDI) e 8 indústrias de alimentos fornecedoras (estavam trabalhando há pelo menos 4 meses com EDI). Outro prérequisito para fazer parte da amostra, é que sejam trocadas, via EDI, informações como pedidos e espelho da nota fiscal.

Na seleção dos varejistas, partiu-se do Ranking 97 da Revista Superhiper (1998), e abordou-se as 10 maiores, com sede em São Paulo. Apenas 5, com duas delas tendo sido recentemente adquiridas por outras redes, cumpriam os pré-requisitos da pesquisa e concordaram em participar da pesquisa. Portanto, a amostra contou com 3 empresas de varejo e mais uma empresa (misto de atacado e varejo) que não estava no Ranking 97 mas foi indicada como pioneira na difusão e uso do EDI no Brasil. A partir destas entrevistas, solicitou-se às empresas que informassem os fornecedores aos quais estavam conectadas via EDI, desde o início do processo. Foram indicadas 14 indústrias, mas apenas 8 cumpriram os critérios para fazer parte da amostra e concordaram em participar.

Não houve preocupação com representatividade estatística da amostra escolhida, até por se tratar de estudo multicaso. Longe de buscar esgotar o tema, este artigo é apenas um primeiro estudo realizado, que abre caminho para diversos estudos mais aprofundados.

\section{Evolução e Mudanças Relacionadas à Tecnologia de Informação}

\subsection{Caracterização Geral das Empresas Pesquisadas}

$\mathrm{A}^{\mathrm{s}}$ $\mathrm{s}$ três redes de varejo entrevistadas respondem por $31,7 \%$ do faturamento do setor. Compreendem empresas de capital nacional e internacional. Por indicação dos fornecedores de tecnologia, incluiu-se um grande atacadista, que opera também como varejista e é um dos pioneiros na utilização do EDI no Brasil. Das quatro empresas entrevistadas, apenas duas operam com Centros de Distribuição (CD). Mesmo nessas empresas, parte da entrega de produtos é feita diretamente nos pontos-de-venda. Todas as pesquisadas têm atuação nacional, possuem mais de 25 lojas no Brasil e são consideradas de grandes porte do setor em que atuam (Ranking 98, 1999).

Os fornecedores foram selecionados a partir da referência dos varejistas, com o único cuidado de buscar-se os que atuam na indústria de alimentos. Essa preferência visava a identificar que existia relação entre a adoção de EDI e a distribuição de produtos com alto grau de perecibilidade. No decorrer da pesquisa, evidenciou-se que fornecedores desse tipo de produto não são pioneiros, ou não elegem tal 
linha de produtos como prioridade na troca de informações (devido à maior complexidade logística associada). Todas as empresas pesquisadas podem ser consideradas grandes (pelo critério Sebrae) por possuírem mais de 600 empregados. Algumas são de capital nacional e outras pertencem a multinacionais. Das oito empresas estudadas, apenas uma não possui negócios relacionados ao processamento de alimentos, estando vinculada à cadeia de produtos de perfumaria, higiene e limpeza doméstica e oral. Essa empresa foi selecionada por ser pioneira, do lado da indústria, nos projetos de adoção de EDI no Brasil.

Tanto no caso dos varejistas como no caso de seus fornecedores, trabalhou-se com grandes empresas. Essa característica é importante, pois como salientam MCGOWAN \& MADEY (1998), grandes empresas têm duas vantagens na implementação de EDI: grandes volumes de transação, que levam a obter maiores benefícios com a adoção e estão em melhor posição para solicitar que os parceiros adotem também a tecnologia. Dada a exigência de sigilo por parte dos entrevistados, as empresas pesquisadas foram analisadas de forma agregada, dividindose apenas em "indústria" e "varejistas".

\subsection{O Processo de Implantação}

\section{a) Etapas Iniciais}

O início do processo variou de empresa para empresa pesquisada. No grupo das indústrias há empresas que iniciaram o EDI com projetos de sistemas proprietários, já no fim da década de 80 (1989). Tais projetos não apresentaram os resultados esperados. Um dos motivos apontados pelos entrevistados foi o período de elevada inflação, no qual os clientes preferiam concentrar seus pedidos no final de cada mês. $O$ processo de adoção de EDI é recente nas empresas pesquisadas. As empresas pioneiras iniciaram o processo.

A partir das entrevistas realizadas é difícil afirmar que a iniciativa de adoção do EDI partiu exclusivamente do varejo ou da indústria. Dentre as oito indústrias visitadas, quatro afirmam que foram convidadas inicialmente por grandes varejistas. Já nas demais, fica evidente a participação de outras instituições na aproximação entre possíveis parceiros, como as empresas de tecnologia (VAN's), a EAN Brasil e o Projeto Sincovaga/FIA/USP.

Quanto aos varejistas, apenas duas empresas afirmaram ter tomado a iniciativa de implantar o projeto incentivadas por reuniões e palestras promovidas pela EAN Brasil. Nenhuma das empresas pesquisadas tentou implementar EDI proprietário, apesar de uma delas ter sido consultada por um fornecedor a respeito dessa possibilidade. Todos os varejistas entrevistados posicionaram-se contra o EDI proprietário por sua natureza restrita em termos de expansão do número de fornecedores. Tal posicionamento se deve ao fato de duas das empresas terem participado ativamente do grupo de trabalho para a tropicalização dos layouts do EDIFACT, serem membros fundadores da EAN Brasil e terem, portanto, um compromisso de apoiar o uso de padrões abertos. As demais foram procuradas por fornecedores que já estavam mais avançados no sistema ou participavam dos projetos pilotos do Movimento ECR Brasil. Das quatro empresas, após os primeiros testes, três resolveram expandir imediatamente o processo e passaram a convidar fornecedores para realizar EDI para a troca de pedidos.

A maioria das empresas do grupo de indústrias entrevistadas afirmou que as instituições que prestam serviço em tecnologia - as VAN's e a EAN Brasil - foram muito importantes no início do processo de adoção da tecnologia, dado o conhecimento de que eram detentoras. Nesse grupo, apenas uma empresa citou o Movimento ECR Brasil como importante aliado no processo. A EAN Brasil e o Movimento ECR Brasil foram mencionados pelos varejistas como agentes importantes no processo, o primeiro nos estágios iniciais do projeto e o segundo a partir de sua criação em 1997.

Quando se procurou avaliar quanto foi investido no processo de adoção de EDI, a maior 
parte dos entrevistados, tanto por parte da indústria quanto do varejo, afirmou que suas empresas nunca estiveram preocupadas em avaliá-los e que eram custos difíceis de serem mensurados por envolverem basicamente algumas mudanças em sistemas de informação, negociação com os clientes/fornecedores e mudanças em processos intra-organização. Fato relevante a ser considerado e que talvez explique a situação é que, paralelamente a adoção de EDI, muitos processos relacionados foram modificados, gerando mudanças as quais exigem diferentes formas de apuração de custos, ainda não sistematizadas pelas empresas. A explicação é justificada, considerando-se o fato de que no processo de adoção de uma tecnologia qualquer existe um período de transição no qual os velhos mecanismos de mensuração e controle de custos tornam-se inadequados antes de surgirem novos mecanismos (ZALTMAN et al., 1976).

O desenvolvimento e a coordenação do processo de adoção de EDI também variaram de empresa para empresa. A maioria dos entrevistados afirmou que são exigidas dos responsáveis pelo projeto visão ampla das áreas de negócio usuárias, facilidade no relacionamento e trânsito por várias áreas da empresa, além de alguma experiência em sistemas. Percebe-se que também no varejo, conforme o projeto de EDI cresceu em termos de parceiros e de número de informações trocadas, as áreas usuárias (comercial e logística) assumiram o controle ou, pelo menos, passaram a se envolver mais no processo.

Parece haver uma tendência cada vez maior de o projeto de EDI tornar-se, tanto na indústria quanto no varejo, um projeto corporativo, principalmente quando outras ferramentas do ECR - como gerenciamento de categorias e reposição automática - passam a ser utilizadas. Essa tendência foi citada pela maioria dos entrevistados como mudança necessária para o sucesso do uso da tecnologia, inclusive em termos de possibilidade de apropriação de benefícios. Assim, surge a tendência de se criar funções de coordenadores de EDI ou ECR, que não estariam diretamente vinculados a qualquer área, mas trabalhariam na formação de uma rede entre indivíduos das diversas áreas impactadas pelo uso da tecnologia. Essa rede interna trabalharia na implementação e na evolução do EDI e de outras ferramentas de ECR. Em um dos varejistas entrevistados isso já é realidade. Foi formado um comitê EDI/ECR, chefiado por um executivo de negócios que tem sob sua responsabilidade os diretores de Informática, Comercial, Logística e Distribuição.

\section{b) Expectativas $X$ Beneficios}

No Quadro 1 observa-se as expectativas das indústrias e dos varejistas ao início do processo de adoção de EDI.

Quanto às expectativas de vantagens que as empresas visualizavam ao início do processo, do lado da indústria, junto com o aumento da agilidade e confiabilidade na troca de informações, foi evidente a preocupação com a melhoria no serviço ao cliente, que traria impactos nos níveis de desabastecimento e conseqüentes perdas de vendas. A integração das informações, mediante a automação de processos, poderia ser também uma das formas de profissionalizar o processo. $\mathrm{O}$ ganho de custos era visualizado basicamente em termos de menor necessidade de vendedores, o que pode ser caracterizado como uma visão equivocada por parte das empresas uma vez que, num momento seguinte, entenderam que o vendedor não desapareceria, mas deveria se tornar um indivíduo mais preparado para negociar outros aspectos mercadológicos e não somente preços.

Nos varejistas, até pelo fato de a maioria ter iniciado o projeto mais tardiamente, a visão que essas empresas tinham do EDI era mais clara a respeito das possibilidades oferecidas pela tecnologia. As expectativas demonstradas (Quadro 1), como redução nos prazos de entrega, maior agilidade na colocação de pedidos, mudança na relação com fornecedores dada a mudança no perfil do seu vendedor, redução de estoques, mostram os varejistas mais direcionados para melhorar o processo de suprimento de forma quantitativa. 
Quadro 1 - Expectativas antes da adoção.

Fonte: dados de entrevista.

\begin{tabular}{|c|c|}
\hline Indústria & Varejo \\
\hline $\begin{array}{ll}\text { - } & \text { maior agilidade e confiabilidade na troca de } \\
& \text { informações; } \\
\text { - } & \text { maior automação de processos e conseqüente } \\
& \text { integração das informações; } \\
\text { - } & \text { melhor atendimento ao cliente, diminuindo o } \\
& \text { desabastecimento e a dependência da visita do } \\
& \text { vendedor; } \\
\text { - } & \text { aumento das vendas, via diminuição do } \\
& \text { desabastecimento; } \\
\text { - } & \text { redução do custo de venda, por meio da } \\
& \text { diminuição do número de vendedores; } \\
\text { - } & \text { Possibilidade de conhecer melhor e de forma } \\
& \text { mais rápida a demanda dos seus clientes, sem } \\
& \text { depender do vendedor para tanto. }\end{array}$ & $\begin{array}{ll}\text { - } & \text { redução de custos; } \\
\text { - } & \text { redução nos prazos de entrega e maior agilidade } \\
& \text { no recebimento; } \\
\text { - } & \text { maior agilidade na colocação dos pedidos; } \\
\text { - } & \text { maior precisão nas informações trocadas; } \\
\text { - } & \text { maior integração de processos administrativos; } \\
\text { - } & \text { redução de estoques; } \\
\text { - } & \text { redução de mão-de-obra, diminuindo o trabalho } \\
& \text { da área de compras; } \\
\text { - } & \text { mudança na relação com fornecedores, mediante } \\
& \text { mudança no perfil do seu homem de vendas, que } \\
& \text { passaria a ser um profissional preocupado com } \\
& \text { posicionamento da marca; } \\
\text { - } & \text { menor preocupação com reposição e maior com } \\
\text { exposição. }\end{array}$ \\
\hline
\end{tabular}

Quanto a tornar o processo de suprimento menos dispendioso, pode-se afirmar que, apesar do discurso da maioria dos entrevistados, nenhuma das empresas realizou sequer uma análise dos investimentos necessários, tampouco estimativas de quais seriam os ganhos quantitativos a partir das mudanças empreendidas. Quase todas as empresas, porém, acreditavam que o processo exigiria mudanças de natureza qualitativa, em termos de redesenho de processos e do próprio trabalho do vendedor. Pelos dados apresentados, infere-se que a indústria, ao início do processo, percebia a mudança na função do vendedor como uma das formas de reduzir custos e ter menor dependência dele (como "tirador" de pedidos e tomador de informações sobre o mercado). $\mathrm{O}$ varejo, ao contrário, queria poder contar com um profissional mais preocupado com posicionamento da marca e menos com preço.

Segundo as empresas que participaram do estudo, ao longo do processo de adoção foram obtidos alguns benefícios em atividades intraorganização (gestão interna) e no relacionamento com clientes e/ou fornecedores (interorganizações). Nos Quadros 2 e 3 são identificados, respectivamente, os benefícios quantitativos $\mathrm{e}$ qualitativos.

Fator interessante a ser discutido refere-se ao contraponto que pode ser feito entre as expectativas das empresas envolvidas na iniciativa de adoção e os benefícios por elas obtidos após o processo realizado. A indústria verificou redução no custo de compra/venda, não sendo ainda evidente, porém, a diminuição do contingente de vendedores. Tal aspecto pode ser fruto de duas situações: à medida que o processo evolui, percebe-se a necessidade de vendedores com perfil de consultor de marketing, ou seja, capazes de propor ações para fazer crescer a marca da empresa no mercado; outro refere-se a que, como poucos clientes se encontram conectados, ainda sobram muitos a serem atendidos pelo método tradicional de "tirar pedidos", logo, os vendedores descartados (até pelo fato de não se adaptarem ao novo perfil requerido) do processo via EDI, acabam reaproveitados para atuar em outros clientes. De modo geral, comparando 


\section{Quadro 2 - Benefícios quantitativos.}

Fonte: questionários/entrevistas.

\begin{tabular}{|c|c|c|}
\hline & Indústria & Varejo \\
\hline - Intra-organização & $\begin{array}{l}\text { - redução de custo no processo de } \\
\text { compra e venda, que poderá } \\
\text { reduzir o preço final do produto; }\end{array}$ & $\begin{array}{ll}\text { - } & \text { redução de custo; } \\
\text { - } & \text { políticas de estoques mais adequadas, } \\
& \text { com conseqüente redução de quebra; } \\
\text { - } & \text { aumento do giro; } \\
\text { - } & \text { promoções mais eficientes, baseadas } \\
& \text { em queda de custos; } \\
\text { - } & \text { preço mais eficiente; } \\
\text { - } & \text { aliado ao gerenciamento por } \\
& \text { categorias, o EDI garante sortimento } \\
& \text { mais eficiente. }\end{array}$ \\
\hline - Interorganizações & $\begin{array}{l}\text { - maior agilidade no atendimento ao } \\
\text { cliente; } \\
\text { - } \text { maior agilidade no tempo entre } \\
\text { pedido e entrega; } \\
\text { - } \\
\text { aumento do volume de vendas para } \\
\text { ambos os parceiros; }\end{array}$ & - \\
\hline
\end{tabular}

Quadro 3 - Benefícios qualitativos

Fonte: questionários/entrevistas.

\begin{tabular}{|l|l|c|}
\cline { 2 - 3 } \multicolumn{1}{c|}{} & \multicolumn{1}{c|}{ Indústria } & Varejo \\
\hline Intra-organização & $\begin{array}{l}\text { - experiência/aprendizado com o processo; } \\
-\begin{array}{l}\text { obriga as empresas a aprimorarem seus processos } \\
\text { internos. }\end{array}\end{array}$ & - \\
\hline \multirow{4}{*}{ Interorganizações } & $-\begin{array}{l}\text { melhoria no atendimento ao cliente, com impactos } \\
\text { positivos na imagem da empresa, o que representa } \\
\text { vantagem competitiva frente a outros fornecedores; }\end{array}$ & $-\begin{array}{l}\text { maior integração da cadeia logística; } \\
\text { disponibilidade de informações mais ricas e confiáveis, } \\
\text { que permitem à empresa agir pró-ativamente; } \\
\text { aumento da satisfação do cliente, com menor número } \\
\text { de devoluções. }\end{array}$ \\
\hline
\end{tabular}

expectativas e benefícios sob a ótica da indústria, avalia-se que foi realizado tudo o que era esperado, com ganhos evidentes no processo de aprendizagem com a tecnologia.

Do lado do varejo, pode-se observar que as expectativas de natureza quantitativa, com foco intra-organização foram alcançadas via benefí- cios relatados pelas empresas entrevistadas. Segundo entrevistados do varejo, porém, fica claro que a idéia de mudar a relação com o fornecedor mediante mudança no perfil do seu vendedor não foi alcançada, segundo entrevistados do varejo. Tal aspecto revela que muito ainda tem de ser feito para mudar a cultura de se 
fazer negócios e para haver melhoria na relação fornecedor e cliente no caso de grandes varejistas e indústrias agroalimentares.

\section{c) O Teste}

De acordo com BENJAMIN et al. (1990), muitas empresas iniciam a adoção de EDI com um projeto-piloto ou teste, que são processos planejados para facilitar o aprendizado organizacional. Neste momento a preocupação é fazer o sistema funcionar e gerenciar os impactos do mesmo na empresa.

Nas empresas pesquisadas, tanto do lado da distribuição quanto do lado da indústria, os projetos-piloto são iniciados com um ponto-devenda e, normalmente, com uma linha de produtos. Como está se analisando empresas pioneiras de ambos os lados, os pilotos foram realizados dois a dois na maior parte dos casos. Apenas um dos varejistas iniciou o projeto tendo do outro lado cinco fornecedores. Trata-se de um caso isolado, com características específicas, como o fato desses fornecedores já terem relativa experiência com outros varejistas e o varejo em questão dispor de um nível de informatização interno alto e já adotar procedimentos de logística, como cross-docking. O cross-docking é um sistema de entrega em que a mercadoria enviada pelo fornecedor, em carga fechada unitizada, é descarregada de um caminhão, passa pela plataforma de carregamento onde é fracionada conforme as necessidades, sendo imediatamente transferida para outro caminhão (para ser entregue no ponto-de-venda), sem permanecer em estoque. $\mathrm{O}$ objetivo dele é que se elimine o tempo de estoque, desde que haja uma sincronia entre pedido, entrega, recebimento e redespacho. Isto configura uma típica situação de just-in-time de entrega.

Um experiência interessante relatada no caso de dois parceiros foi a realização de apresentações do projeto, feitas pelos coordenadores de EDI do cliente e do fornecedor. A idéia dessas apresentações, que foram realizadas em diversas áreas afetadas pelo projeto de EDI dentro da empresa cliente (varejista), era informar o que estava acontecendo, como cada área colaboraria com o projeto e quebrar eventuais resistências. Como resultado, essa empresa foi uma das que enfrentou menores resistências e tem um dos projetos mais avançados do mercado, em termos de abrangência (número de parceiros e áreas envolvidas) e qualidade de resultados.

Os testes têm duração variável, podendo durar de 1 mês a 1 ano, dependendo da quantidade de acertos e mudanças necessárias em cada empresa e do apoio recebido dos diretores/presidente. Apenas em um dos varejistas os testes já duram dois anos e não evoluem, pois a empresa foi adquirida por uma outra rede, que decidiu parar o projeto momentaneamente.

\section{d) Resultados Marcantes}

Do lado da indústria ficou clara a necessidade de rever processos internos, para se obter vantagens com a adoção do EDI. Essa revisão de processos internos descobriu, por exemplo, alguns erros simples que ocorriam no processo manual, mas que faziam a indústria perder vendas. Um exemplo disso foi o fato de se descobrir, na hora de acertar os cadastros de produtos a serem fornecidos, que alguns produtos não eram comprados por alguns clientes sem razão aparente, a não ser desconhecimento do cliente daquele produto em alguns dos seus pontos-de-venda.

Outros dois focos de mudanças foram: a necessidade de se ter cuidados especiais na codificação de produtos e no fluxo de informações direcionados aos vendedores, que nos clientes conectados passam a se preocupar mais com a exposição do que com a reposição, e para tanto tem de estar informados do que se vende para aquela loja.

Dentre os resultados marcantes da experiência para as empresas do lado do varejo, encontram-se:

- a possibilidade de se avaliar o quanto é ineficiente a gestão de estoques; uma das empresas afirmou que baixou estoques de certos produtos de 14 dias para 3 dias, com uma economia quantificada de 40.000 reais/ano; 
outra empresa afirmou que por mais que o EDI não seja a solução de todos os problemas, ainda é um processo superior ao processo manual;

- existe uma redução substancial dos prazos de entrega; primeiro, deixa-se de esperar que o vendedor do fornecedor passe, a cada 7 dias, para retirar o pedido; o pedido é feito no momento necessário e as entregas podem ser feitas em menos de 24 horas.

\subsection{As Mudanças}

Dentro das empresas pesquisadas, fica claro que a adoção de EDI provoca mudanças, tanto nas operações rotineiras internas, quanto na relação empresa-ambiente. Porém, essas mudanças são sentidas apenas à medida que o processo evolui. Percebe-se que as empresas, de ambos os lados, que já estão realizando reposição automática, são as que mais sofrem os impactos do processo.

\section{a) Internas à Empresa}

As mudanças internas representam alterações nas atividades rotineiras provocadas pela introdução do EDI. Na estrutura do sistema de informação mudam os fluxos que passam a fazer parte dele. Exemplo disso são os pedidos recebidos via EDI, que devem ser repassados diariamente aos vendedores que continuarão a visitar as lojas. Algumas empresas já estão transferindo tais informações também via EDI, para o notebook do vendedor. No caso de a indústria receber informações sobre vendas do varejo (sales report), deverá desenvolver formas de tratá-las para que agreguem valor na transação.

Algumas empresas do grupo da indústria que tem EDI a mais tempo, ressaltaram que houve, com o processo de adoção da tecnologia, maior aproximação com o cliente, decorrente principalmente da mudança de abordagem do vendedor. Foi citado também que as atividades de transporte tornaram-se mais profissionalizadas: o transportador passou a cumprir os horários de entrega acertados entre indústria e seus clientes.
A área comercial do grupo das indústrias, segundo dados fornecidos pelas empresas pesquisadas na segunda fase do trabalho de campo, sofreu diversos impactos:

Na organização da função vendas:

- no papel da força de vendas - que deixou de tirar pedidos e passou a monitorar mais de perto o comportamento dos produtos loja a loja. O vendedor passou a ter mais tempo para atividades de merchandising e para negociar com a loja no caso de os parâmetros estarem mal dimensionados, causando ruptura; deixou de "empurrar" produtos para o varejista e passou a implementar ações para aumentar o giro dos produtos;

- no perfil do vendedor - apesar de ter havido mudanças em sua forma de atuação, sua remuneração não se alterou; ele continua sendo recompensado da mesma maneira. A argumentação das empresas quanto a esse aspecto é que ainda não existe massa crítica para se alterar o sistema e alguns vendedores atuam em lojas com e sem EDI. Uma das empresas relatou que procura mostrar ao vendedor que, com esse novo perfil, ele teria maiores possibilidades de carreira;

- no produto vendido pela indústria - deixa de ser apenas um complexo de atributos tangíveis, passando a incluir serviços que vão desde condições logísticas mais favoráveis para ambos os parceiros, até chegar ao novo comportamento do vendedor, que passa a ser um consultor de marketing da loja;

No varejo, alguns impactos evidentes pela adoção de EDI podem ser citados:

- na estrutura do sistema de informação principalmente no momento em que o varejista decide passar para o seu fornecedor posição de estoques e relatórios de vendas. Ressalta-se como condição necessária para tal procedimento a informatização dos pontosde-venda e o link dessas informações com as de retaguarda e do Centro de Distribuição, caso a empresa o tenha;

- na organização da função compras - na qual o comprador perde grande parte do seu poder; 
- no custo e tempo do pedido - com o ganho de agilidade esperado;

- na gestão de estoques em tempo real e integração da demanda do cliente ao sistema de operação. Há dependência direta da estrutura do fluxo de informações captadas nos terminais de ponto-de-venda, considerandose loja a loja, servindo de input para o cálculo da reposição pelo Centro de Distribuição ou pelo fornecedor.

Observação relevante refere-se a que, tanto para o varejo quanto para a indústria se apropriarem de alguns importantes benefícios do EDI, seria desejável que redesenhassem, de forma conjunta, a gestão de atividades de promoção, buscando repassar as demandas dos clientes finais para toda a cadeia.

\section{b) Na Relação Empresa-Ambiente}

As mudanças na relação empresa-ambiente são representadas por alterações nas relações entre clientes e fornecedores (varejo e indústria) e também entre estes e outros agentes envolvidos no processo de adoção de EDI, como fornecedores de tecnologia de informação e transportadoras. Houve evolução significativa na relação de troca; um dos fornecedores citou o fato de ter deixado de "empurrar" mercadorias de baixo giro para o varejo. Para a indústria, a questão do poder detido no canal não se alterou beneficiando a ela ou ao varejo exclusivamente; ambos partilham os benefícios, o que parece indicar uma evolução na direção de parcerias do tipo ganha-ganha. As indústrias que dispõem da tecnologia há mais tempo afirmam que o fato lhes confere imagem de modernização. Esse dado é também verificado nos varejistas.

A importância das atividades de transporte já foi percebida pelas indústrias mais experientes no uso do EDI, mas poucas já estenderam a tecnologia para a troca de informações com transportadoras. Ou seja, muitas indústrias ainda não exigem dos transportadores papel mais próativo no processo. Ficou evidenciado que mesmo as empresas mais avançadas no uso de EDI com clientes não percebiam com clareza o papel do operador logístico; algumas afirmaram que o oferecido por empresas do ramo no mercado brasileiro deixava muito a desejar na relação custo-benefício.

De acordo com alguns varejistas, algumas vezes os fornecedores não conseguem cumprir os prazos de entrega acordados, por motivos considerados absurdos pelo varejo, como caminhão não disponível para fazer a entrega ou falta de embalagens. Outras vezes os fornecedores não cumprem os horários de corte estabelecidos (no início da troca de informações determina-se até que horas o varejo pode enviar o pedido para a VAN e o horário no qual os fornecedores acessam a caixa postal e coletam a informação). Devido às necessidades do varejo serem muito dinâmicas, a automatização do processo acaba por eliminar os "colchões" ou estoques para suportar deficiências na cadeia; caso o fornecedor não entregue nos horários e dias combinados, poderá haver rupturas e, assim, perdas de vendas.

Apesar de não ter sido perguntado diretamente nas entrevistas, algumas empresas deixaram claro que o processo de adoção acaba por fazer as áreas de sistemas das empresas conversarem entre si para resolverem dúvidas na implantação de tecnologia. A participação das empresas, no início da década de 90 nos trabalhos de tropicalização dos layouts do padrão EDIFACT (padrão adotado pela Europa e Brasil para EDI) junto a EAN e posteriormente no Movimento ECR-Brasil, são atividades que promovem reunião e disseminação de informação entre parceiros, favorecendo o início de muitos processos de adoção de EDI.

No relacionamento indústria-varejo observou-se mudança nas negociações, que agora são feitas em bases anuais e com a presença dos níveis hierárquicos mais altos da empresa. Isso torna as decisões menos pessoais (em termos de preferências do comprador ou do vendedor), mais racionais e profissionalizadas. A devolução de mercadorias cai em níveis muito baixos após a adoção de troca de notas fiscais enviadas algumas horas (ou até um dia) antes da mercado- 
ria. Nos clientes conectados, principalmente nos que já trabalham com reposição automática, existem horários marcados para entregas; nenhuma das empresas, porém, afirmou dar prioridade de entrega só pelo fato de fazer EDI com o cliente; o requisito para um cliente obter prioridade ainda é o fato de ser um cliente de grande volume.

\subsection{Obstáculos à Adoção}

No Quadro 4 são apresentados alguns dos obstáculos identificados pelas empresas pesquisadas. Foram divididos em internos às empresas (intra-organização) e externos, no relacionamento com clientes e/ou fornecedores (interorganizações).

Observa-se no Quadro 4 que, tanto intraorganização como no relacionamento entre elas, as resistências culturais apresentam um importante obstáculo. No momento desta pesquisa, $2^{\circ}$ semestre de 1998 , já se evidenciava a carência de recursos humanos qualificados para a operação com a tecnologia de informação, tanto internamente, como nos serviços de apoio dos fornecedores de tecnologia de informação. A questão de adaptação de diferentes padrões escolhidos pelas empresas, não apareceu nas empresas pesquisadas como um obstáculo, conforme citado na literatura internacional.

\section{Conclusões}

A primeira conclusão que se chega depois dessa breve discussão sobre o uso de EDI na relação entre varejistas e alguns de seus fornecedores é que essa é relativamente recente, mesmo em grandes empresas. Esse fator, ao mesmo tempo que torna o tema instigante, traz uma certa dose de frustração para o pesquisador por não ter um processo ainda evoluído o suficiente para mensurar resultados quantitativos mais significativos e descrever mudanças surpreendentes na estruturação das empresas.

Dentre as indústrias, apenas duas colocaram o EDI como meta estratégica e executaram o projeto na expectativa dos resultados a serem obtidos no longo prazo. Isso tornou-se evidente porque foram criadas, nessas empresas, áreas e/ou cargos com responsabilidade institucionalizada sobre o processo de adoção de EDI, tendo em vista inclusive o próprio ECR. Nas outras empresas, ficou claro o papel do "líder", ou seja, no início do projeto o coordenador era, em alguns casos, a única pessoa a ter claro os benefícios a serem obtidos e a buscar apoio interno para a sua execução.

Devido aos diferentes estágios do processo de adoção de EDI e de outras ferramentas de ECR em que se encontram as empresas pesquisadas, ficou evidente que ao longo do processo todas começaram a perceber a importância de tornar as novas tecnologias e ferramentas de gestão metas estratégicas. Perceberam também, no caso de implantá-las apenas parcialmente (devido a resistências diversas), que não alcançariam os resultados esperados. Um fator que acabou alterando a forma de as empresas visualizarem a tecnologia foi o aprendizado realizado ao longo do processo. Muitas delas iniciaram-no incentivadas pelo convite de um importante parceiro de negócios, ou simplesmente pela crescente divulgação da importância das "novas ferramentas de gestão para canais de distribuição" e pelo fascínio exercido pelas promessas de ganhos em redução de custos e aproximação com clientes.

$\mathrm{O}$ que algumas empresas pioneiras perceberam, não no momento de iniciar o processo, mas no decorrer dos primeiros testes, é que o modelo básico não trazia os ganhos prometidos em termos de melhoria da agilidade, nem de redução dos custos. Na verdade, a troca de pedidos no EDI era apenas um "fax" de luxo. Os ganhos tornaram-se evidentes na medida que se implantou a reposição automática. As empresas que iniciaram a implantação em 1996/1997 já tinham essa visão consolidada e perceberam que quanto mais rápido avançassem no processo, mais rapidamente os ganhos poderiam ser observados. Nesse aspecto houve uma componente importante, que foi a quebra das resistências internas. Enquanto não surgiram resultados 
Quadro 4 - Obstáculos.

Fonte: questionários/entrevistas.

\begin{tabular}{|c|c|c|}
\hline & Indústria & Varejo \\
\hline Intra-organização & $\begin{array}{ll}\text { - } & \text { resistência a cultura da empresa, } \\
\text { principalmente por parte dos } \\
\text { vendedores; } \\
\text { - } \\
\text { pessoal desqualificado para } \\
\text { operação: compradores e } \\
\text { vendedores sem o perfil adequado; } \\
\text { - } & \text { dificuldade no desenvolvimento do } \\
\text { sistema e incompatibilidade com os } \\
\text { sistemas internos. }\end{array}$ & $\begin{array}{l}\text { - } \text { dificuldades de desenvolvimento, } \\
\text { software e incompatibilidade com } \\
\text { os sistemas existentes; } \\
\text { - } \text { pessoal desqualificado para } \\
\text { operações; } \\
\text { - } \\
\text { resistência da cultura da empresa. }\end{array}$ \\
\hline Interorganizações & $\begin{array}{ll}\text { - } & \text { resistência de algumas áreas do } \\
& \text { cliente; } \\
\text { - } & \text { legislação governamental: a nota } \\
& \text { fiscal trocada eletronicamente não } \\
& \text { tem valor legal; } \\
\text { - } & \text { atualização de cadastros. }\end{array}$ & $\begin{array}{l}\text { - } \text { serviço de apoio dos fornecedores } \\
\text { de TI; } \\
\text { - } \text { resistência dos fornecedores. }\end{array}$ \\
\hline
\end{tabular}

quantitativos, muitas pessoas não acreditaram no processo, ganhando destaque e, como tal, oferecendo obstáculos e, algumas vezes, acabaram influenciando outros a dele não participarem.

A ausência de mudanças surpreendentes em termos de estrutura tem uma razão clara. A adoção de uma tecnologia de informação como o EDI, influencia não somente a operação de retaguarda do varejista, mas também a retaguarda e a linha de frente (área de vendas) do fornecedor, além das transações interempresas. Nessa situação têm-se duas culturas empresariais interagindo, o que torna o processo de mudança lento e sujeito a resistências diversas. Para contornar esse obstáculo, um fator considerado essencial pelas empresas pesquisadas é o envolvimento da cúpula decisória da empresa no processo. O ideal, segundo os fornecedores de tecnologia, seria que a adoção de EDI fizesse parte da estratégia das empresas e não fosse, como é em muitos casos, um ato empreendedor de um gerente. Tanto é um ato empreendedor, que em algumas empresas existiram recompensas financeiras e promoções para os idealizadores do processo.
Uma saída para enfrentar as resistências que surgem ao longo do processo de adoção de EDI é que varejistas e fornecedores organizem apresentações conjuntas, realizadas pelos coordenadores do processo nos dois parceiros, nas áreas mais afetadas pelas mudanças oriundas do EDI. Isso acaba se tornando uma forma de se institucionalizar o processo, motivando $\mathrm{e}$ envolvendo todos, uma vez que a idéia desta tecnologia é compartilhar e disseminar informação ao longo da cadeia. Sugere-se que as referidas apresentações sejam realizadas nas áreas de logística (incluindo os centros de distribuição, caso existam), comercial e informática.

Um fator que deve ser desmistificado, à medida que as empresas evoluem no processo de adoção de EDI, é a vantagem que muitas empresas de varejo enxergam, inicialmente, na possibilidade de não trabalharem com estoques, dado que o fornecedor pode fazer entregas todos os dias. Na verdade, não se trata de transferir os estoques da loja ou do centro de distribuição do varejista para o fornecedor. Segundo um dos fornecedores entrevistados, em alguns casos, 
como no caso de um cliente onde as entregas eram feitas por loja, o custo de entregar diariamente inviabilizava a operação. Após algumas negociações, os dois parceiros chegaram a conclusão que, apesar da posição de estoques ser passada diariamente, as entregas seriam realizadas duas vezes na semana de forma que a loja ficaria abastecida e o fornecedor não teria custos adicionais de entregar pouca mercadoria todo dia. Vale dizer, que não é a tecnologia sozinha que resolve todos os problemas ao longo da cadeia de suprimentos, mas além de tê-la, os parceiros deverão sentar à mesma mesa e entrar em um acordo que seja bom para ambas as partes e agregue valor para o cliente final.

Um fator que deve ser trabalhado é o nível de confiança entre os parceiros comerciais. Sem confiança e vontade de trabalhar em conjunto, todas as novas tecnologias, inclusive o EDI, tornam-se apenas modismos e tentativa de passar uma imagem de vanguarda tecnológica não verificada na prática.

\section{Referências Bibliográficas}

ALCÂNTARA, R.L.C.: A Gestão estratégica dos canais de distribuição. Um exame da evolução do atual estágio do relacionamento entre atacado de entrega e a indústria. (Tese de doutoramento). São Paulo, Fundação Getúlio Vargas, nov.1997.

ANVARI, M.: "Electronic data interchange and inventories." In: CHIKÁN, Attila. Current trends in inventory research. Amsterdam: Elsevier Science Publishers B.V., 1992.

BAKOS, J.Y.: "Information links and electronic marketplaces. The role of interorganizational information systems in vertical markets." Journal of Management Information Systems, p.15-34, Fall, 1991.

BANERJEE, S. \& GOLHAR, D.Y.: "Electronic data interchange: characteristics of users and nonusers." Information Management. n.26, 1994

BELL, R. \& DAVIES, R.: "The changing structure of food retailing in Europe: the implications for strategy." Long Range Planning. v.30, n.6, 1997.

BENJAMIN, R.I.; LONG, D.W. \& MORTON, M.S.S.: "Electronic data interchange: how much competitive advantage?" Long Rangeg Planning. v.23, n.1, 1990.

BOWERSOX, D.J. \& CLOSS, D.J.: Logistical management: the integrated supply chain process. NY: McGraw-Hill, 1996.

BRECHTEL, C. \& JAYARAM, J.: Supply chain management: a strategic perspective. The International Journal of Logistics Management. v.8, n.1, p.15-34, 1997.

BROWNING, J.: Pocket Information Technology. England: The Economist Books, 1997.
COLLA, E.: La grande distribution en Europe. Évolution des formules, des stratégies et des structures des entreprises. Paris: Vuibert, 1997.

COOPER, M.C.; LAMBERT, D.M. \& PAGH, J.D.: "Supply chain management: more than a new name for logistics." The International Journal of Logistics Management. v.8, n.1, p.1-13, 1997.

EAN Brasil: Guia de Implementação EDI/EANCON. 24/08/1998.

FARINA, E.M.M.Q. \& ZYLBERSZTAJN, D.: "Competitividade e organização das cadeias agroindustriais." IICA - Instituto Interamericano de Cooperação para a Agricultura. Costa Rica, 1994.

GOTTARDI, G. \& BOLISANI, E.: "A critical perspective on information technology management: the case of electronic data interchange." International Journal of Technology Management. v.12, n.4. 1996.

HANDFIELD, R.B. \& NICHOLS, E.L. Jr.: Introduction to supply chain management. New Jersey: Prentice Hall, 1999.

JOINT Industry Project on Efficient Consumer Response: A Best Practices Model. A Best Practices Committee. 1995.

KEH, T. \& PARK, S.Y.: "To Market, to market: the changing face of grocery retailing." Long Range Planning. v.30, n.6, p.836-846, 1997.

KONSYNSKI, B.R. \& McFARLAN, E.W.: "Information partnerships - shared data, shared scale." Harvard Business Review. v.68, n.5, p.114-121, sept./oct. 1990. 
MALTZ, E. \& SRIVASTAVA, R.K.: "Managing retailer-supplier partnerships with EDI: evaluation and implementation." Long Range Planning. v.30, n.6, 1997.

McGROWAN, M.K. \& MADEY, G.R.: "Adoption and implementation of electronic data interchange." In: LARSEN, Tor \& McGUIRE, Eugene. Information Systems Innovation and Diffusion. USA: Idea Group Publishing, 1998.

MARCUSSEN, C.: "The effects of EDI on industrial buyer-seller relationships: a network perspective." International Journal of Purchasing and Materials Management. aug. 1996.

NAVAJAS, P.F. \& TAKAOKA, H.: "Um estudo sobre o intercâmbio eletrônico de dados (EDI) por uma empresa do ramo de varejo." Anais do $2^{\circ}$ SEMEAD - Seminário em Administração. FEA/USP São Paulo, 1997.

NIERDERMAN, F.: "The diffusion of electronic data interchange technology." In: LARSEN, Tor \& McGUIRE, Eugene. Information Systems Innovation and Diffusion. USA: Idea Group Publishing, 1998.
RANKING 97: Revista Superhiper, abr/1998.

RANKING 98: Revista Superhiper, maio/1999.

SILVA, A.L. \& BATALHA, M.O.: "Marketing estratégico aplicado a firmas agroindustriais. In: BATALHA, Mário O. (coord.) Gestão agroindustrial. São Paulo: Atlas, 1997.

STERN, L.W. \& EL-ANSARY, A.I.: Marketing Channels. $4^{\mathrm{a}}$ ed., Englewood Cliffs: Prentice-Hall, 1992.

VIJAYASARATHY, L.R. \& ROBEY, D.: “The effect of EDI on market channel relationships in retailing." Information \& Management, n.33, p.73-86, 1997.

YIN, R.K.: Case study research. Design and methods. $2^{\text {a }}$ ed., USA: Sage Publications, 1994.

ZALTMAN, G.; DUNCAN, R. \& HOLBEK, J.: Innovations and organizations. USA: John Willey \& Sons, 1973.

\title{
THE IMPACT OF INFORMATION TECHNOLOGY ON THE SUPPLY CHAIN MANAGEMENT: A MULTICASE STUDY IN EDI ADOPTION BETWEEN THE AGRIFOOD INDUSTRY AND RETAILERS
}

\begin{abstract}
Information technology has changed the patterns of coordination among the different linkages of supply-chains. Coordination can be understood as the ability to transfer information, incentives and controls throughout the sequential stages which integrate the set of activities indispensable to serve the market (FARINA \& ZYLBERSZTAJN, 1994). The sum of these stages is currently known as Supply-Chains. This paper discusses cases of adopting a specific information technology, EDI (Electronic Data Interchange), as an integration tool between the food industry and retailers. It was found that the adoption process is too recent to measure significative quantitative results, but it is possible to observe changes in the frequency of stockouts, level of stocks and increased sales as a consequence of greater merchandise availability. Qualitative changes can be seen such as the alterations of the traditional salesmen function, the greater interaction among technical areas with shared learning of the new uses of this technology and the role of trust between business partners.
\end{abstract}

Key words: supply chain, information technology, EDI. 